\title{
Pelatihan Membuat Media Promosi Sederhana dengan Aplikasi Canva di Yayasan Desa Hijau
}

\author{
Ety Nurhayaty ${ }^{1}$, Ratnawaty Marginingsih ${ }^{2}$, Isnurrini Hidayat Susilowati ${ }^{3}$, Eigis \\ Yani Pramularso ${ }^{4}$ \\ 1,2,3,4Universitas Bina Sarana Informatika \\ email: 1ety.eyy@bsi.ac.id, 22ratnawaty.rmg@bsi.ac.id, 3isnurrini.ihs@bsi.ac.id, \\ 4eigis.eyp@bsi.ac.id
}

\begin{abstract}
Abstrak
Saat ini di era industry 4.0, media promosi sering dibagi kedalam dua bagian yaitu media online dan offline. Media promosi online, biasanya dengan menggunakan media sosial, marketplace dan lain-lain, sedangkan untuk promosi secara offline bisa menggunakan salah satu atau gabungan dari media banner, pamplet, spanduk, brosur dan lain-lain. Namun apapun media yang dipilih, tetap harus memiliki desain yang baik, unik dan mudah diingat oleh masyarakat agar mereka tergerak untuk melakukan apa yang disampaikan tersebut. Olehkarena itu pengenalan media promosi sekaligus pelatihan ini diterapkan pada mitra pengabdian masyarakat di Yayasan Desa Hijau yaitu sebuah yayasan yang bergerak di bidang sosial kemasyarakatan, yang kegiatannya banyak berhubungan dengan masyarakat baik sebagai donatur dan penerima. Setelah dilakukan pemetaan masalah, bahwa saat ini yayasan dalam melaksanakan program banyak menggunakan jasa orang lain untuk mendesain media promosi, padahal kegiatan yang dilaksanakan kadang lebih dari satu dan dalam waktu yang berdekatan, sehingga dana yang dihabiskan untuk jasa desain lumayan besar yang jika diakumulasi bisa mencapai Rp.2.040.000 2.500.000/thn disesuaikan dengan program yang diadakan. Maka pada akhirnya disepakatilah pada pengabdian masyarakat kali ini melakukan pelatihan membuat media promosi dengan aplikasi canva, sebagai aplikasi yang relatif mudah d pahami, murah dan bisa dilakukan melalui handphone peserta yang berbasis android. Kegiatan Pengabdian Masyarakat ini dilakukan dengan metode ceramah, demonstrasi dan pratikum. Hasil dari kegiatan ini peserta dapat menerima pengetahuan dan dapat menggunakan aplikasi Canva.
\end{abstract}

Kata Kunci: Pelatihan, Media Promosi, Canva

\begin{abstract}
Currently in the era of industry 4.0, promotional media are often divided into two parts, namely online and offline media. Online promotion media, usually using social media, marketplaces and others, while offline promotions can use one or a combination of banner media, pamphlets, banners, brochures and others. However, whatever media is chosen, it must still have a good design, unique and easy to remember by the public so that they are moved to
\end{abstract}


do what is conveyed. Therefore, the introduction of promotional media as well as this training is applied to community service partners at the Desa Hijau Foundation, a foundation engaged in social activities, whose activities are related to the community both as donors and recipients. After mapping the problem, that currently the foundation in implementing the program uses the services of many other people to design promotional media, even though the activities carried out are sometimes more than one and in close time, so the funds spent on design services are quite large which if accumulated can reach up to Rp. IDR 2,040,000 2,500,000/year according to the program held. So in the end, it was agreed that at this time of community service, training on making promotional media with the Canva application, as an application that is relatively easy to understand, cheap and can be done through participant's mobile phones based on Android, was agreed. This Community Service activity is carried out using lecture, demonstration and practical methods. As a result of this activity participants can receive knowledge and can use the Canva application.

Keywords: Training, Media Promotion, Canva

\section{Pendahuluan}

Industry 4.0 saat ini menjadikan semua pihak harus beradapatasi dengan cepat di berbagai bidang guna memanfaatkan era ini menjadi peluang pada bidangnya masing-masing. Pemanfaatan era ini tentu dilakukan dengan cara yang wajar dan positif yaitu dalam hal mempermudah komunikasi dan memperoleh informasi. Era ini adalah masa ketika informasi mudah dan cepat diperoleh serta disebarluaskan menggunakan teknologi digital.

Terkait dengan era digital ini salah satu pemanfaatannya adalah sebagai media untuk melakukan promosi. Dalam tulisan Unonongo, dkk (2015) promosi ini bisa melalui komunikasi massa dan promosi secara langsung atau biasa kita kenal dengan door to door melalui iklan atau memasang banner, spanduk, sebar pamplet dan lain-lain

Adanya promosi menjadikan barang dan jasa yang dibuat dapat dikenal ke khalayak. Dimana (Maulidasari, 2021) menuliskan bahwa kegiatan promosi berfungsi sebagai alat untuk mempengaruhi konsumen dalam kegiatan pembelian atau penggunaan jasa sesuai dengan apa yang dibutuhkan oleh konsumen tersebut, bahkan Waluya (2015) mengatakan bahwa promosi berdampak signifikan terhadap pendapatan zakat, infak, shadaqoh (ZIS) pada lembaga/yayasan yang di Kelola bahkan (Ghalib, 2019) menyatakan promosi melalui media social, bahkan mampu menaikkan omset dan keuntungan usaha.

Promosi menjadi salah satu bauran pemasaran bagaimana komunikasi produk tersampaikan dengan baik sehingga banyak pihak yang nantinya tertarik dengan produk yang ada.

Untuk membuat design promosi yang menarik, diperlukan aplikasi. Salah satu aplikasi yang dapat digunakan sebagai media promosi adalah aplikasi Canva. Canva merupakan program design online yang menyediakan berbagai alat editing untuk 
membuat berbagai desain grafis, desain grids, mudah dipahami, meskipun masih pemula (Wardhanie, 2020). Canva menjadi aplikasi yang dipilih untuk membuat desain grafis yang dilakukan secara online dan gratis dengan banyaknya pilihan template untuk pembuatan desain seperti poster, logo, media sosial animasi, video, kartu, kolase foto selebaran dan lain-lain flayer. Adanya aplikasi Canva ini menjadi satu dari alternatif pilihan yang dapat dimanfaatkan sesuai dengan template yang ada untuk berbagai bidang baik sosial, ekonomi, politik dan sebagainya.

Yayasan Desa Hijau yang bergerak di bidang sosial juga tidak lepas dengan permasalahan yang terkait dengan promosi. Yayasan masih terkendala dengan kurang tersebarnya informasi (promosi) keberadaan Yayasan dan kegiatan yang dilaksanakan oleh Yayasan kepada masyarakat, akibatnya jumlah penyumbang dana/donatur masih terbatas dan jumlah penerima bantuan juga belum merata. Aktivitas yayasan belum diketahui secara merata sehingga betapapun baik dan beragamnya program yang dilakukan, dan mempunyai nilai manfaat yang tinggi, namun tanpa dukungan promosi yang baik, maka dampaknya akan terasa biasa saja.

Berdasarkan informasi yang diperoleh penyebab kurang tersebarnya informasi tentang yayasan dan kegiatannya itu karena:

1. Yayasan belum memiliki tenaga khusus untuk mengelola berbagai platform online, seperti website, dan media social, sehingga kadang info belum ter-update secara maksimal

2. Ketika membuat kegiatan, promosi secara offline juga belum maksimal, karena selama ini, banyak mengandalkan pihak luar untuk desain bahan promosinya, sehingga anggaran dana untuk itu semakin besar, apalagi jika ada beberapa kegiatan rutin berbeda dalam rentang waktu yang dekat.

Disinilah peran penting promosi dibutuhkan. Menurut (Halim, 2013) promosi menjadi media yang digunakan memperkuat brand image suatu produk yang sudah ada sekaligus mengenalkan produk berupa barang dan jasa yang baru. (Alma and Hurriyati, 2009) mengemukakan bahwa "promosi merupakan salah satu penentu keberhasilan suatu program. Betapapun berkualitasnya suatu produk, bila konsumen belum pernah mendengarnya dan tidak yakin bahwa produk tersebut akan berguna bagi mereka, maka mereka tidak akan pernah membelinya". Menurut (Valentino, 2020) dalam membuat media promosi, dibutuhkan desainer grafis agar dapat menarik minat masyarakat.

Menurut (Tanjung and Faiza, 2019) Canva adalah program desain online yang menyediakan bermacam peralatan seperti poster,presentasi, template, selebaran, resume, pamflet, brosur, grafik, info grafis, spanduk, sertifikat, ijazah, kartu undangan, kartu nama, kartu pos, kartu ucapan terima kasih, label, logo, penanda buku, buletin, sampul buku, sampul CD, wallpaper desktop, editing foto, gambar mini youtube, cerita instagram, sampul facebook, dan kiriman twitter. Untuk penggunaan canva sendiri meliputi membuat akun canva, kemudian membuat desain, lalu memilih background, dilanjutkan mengedit background, seterusnya menambahkan teks, dan terakhir mengunduh atau membagikan desain(Rahmatullah, Inanna and Ampa, 2020). 
Pengunaan aplikasi Canva juga sudah banyak dimanfaatkan untuk kegiatan dalam pengabdian masyarakat untuk berbagai bidang seperti yang dilakukan (Santi et al., 2020) yang malakukan pelatihan untuk mahasiswa wirausaha berupa pembuatan logo dengan aplikasi Canva. Pengabdian masyarakat oleh (Sholeh, Rachmawati and Susanti, 2020) dilakukan pada UMKM kecamatan Sedayu dengan bentuk pelatihan membuat konten gambar pada media sosial sebagai upaya mempromosikan hasil produk UKM dangan menggunakan aplikasi Canva. Dalam penelitian oleh (Wicaksana, Atmadja and Asmira, 2020) penggunaan Canva dapat digunakan sebagai poster dimana hasilnya menunjukkan pengembangan poster kesehatan pada usia remaja sekolah layak digunakan dalam kegiatan pembelajaran di sekolah dan hasilnya efektif dengan hasil belajar siswa yang baik dengan adanya poster tersebut yang dibuat dari aplikasi Canva.

Tujuan yang ingin dicapai dari kegiatan pengabdian adalah memberikan pelatihan berupa belajar membuat desain promosi untuk membuat medianya, seperti desain banner atau spanduk, leaflet dan lainnya dengan bantuan aplikasi Canva, sehingga masalah yang terjadi yayasan Desa Hijau dapat teratasi. Manfaat dari pelatihan ini 1)kemampuan pengurus dan relawan yayasan dalam membuat desain lebih meningkat dan menghemat pengeluaran sekitar Rp.2.040.000 - 2.500.000/thn, yang digunakan untuk membayar jasa desain banner atau media promosi dalam setiap kegiatan yang dilakukan, 2) bisa membuka jasa membuat desain promosi dimana hasilnya dapat menjadi salah satu sumber pemasukan bagi Yayasan untuk mengadakan kegiatan lainnya

Berdasarkan hasil analisis situasi seperti ini, maka kami diskusikan materi yang setidaknya bisa membantu mengatasi masalah yang ada akhirnya disepakati program pengabdian masyarakat dengan tema" Pelatihan Membuat Media Promosi Sederhana Dengan Aplikasi Canva Di Yayasan Desa Hijau"

\section{Metode}

Metode yang digunakan pada pelaksanaan kegiatan pengabdian masyarakat adalah Metode Ceramah, Demonstrasi dan Praktikum. Peserta pelatihan merupakan pengurus dan relawan Yayasan Desa Hijau yang beralamat di Jl. Masjid At-Tauhid Jl. H. Kuming 2 No.123, RT.4/RW.12, Kedaung, Pamulang, Tangerang Selatan Metode Ceramah digunakan untuk menjelaskan materi dasar-dasar desain grafis dan perkenalan aplikasi Canva itu sendiri. Metode Demonstrasi digunakan untuk memberikan contoh cara membuat desain promosi menggunakan Canva. Sedangkan Metode Praktikum digunakan untuk peserta dalam mempraktikan pembuatan desain menggunkan Canva sesuai dengan kreativitas masing-masing peserta yang mengikuti pelatihan .

\section{Hasil dan Pembahasan}

Kegiatan pengabdian masyarakat dengan tema "Pelatihan Membuat Media Promosi Sederhana Dengan Aplikasi Canva Di Yayasan Desa Hijau" dilaksanakan pada hari sabtu, 27 Maret 2021 yang dilaksanakan dengan protokol ketat dan dilaksanakan dengan metode daring, via live Youtube dan zoom, walaupun ada beberapa yang 
berada dilokasi untuk belajar secara langsung. Adapun pelaksanaan kegiatan ini terdiri dari pembukaan, penjelasan materi pentingnya promosi yang disampaikan oleh Ibu Isnurrini Hidayat Susilowati, S.E., M.M. dan kemudian dilanjutkan dengan materi canva sekaligus pratikum yang dipandu oleh Ibu Ratnawaty Marginingsih, S.E., M.M. melalui zoom meeting /youtube dan dibantu beberapa asisten tutor di lokasi untuk meng-handle peserta dalam mempraktikkan materi di handphone/laptopnya masing-masing.

Sebelum masuk pada sesi praktik, peserta dibekali dengan materi tentang pemasaran khususnya promosi yang nantinya diharapkan mampu diaplikasikan pada kegiatankegiatan yang diselenggarakan oleh Yayasan.

\section{A. Pengertian Promosi}

Dalam (Garaika, 2019) ada beberapa pengertian menurut para ahli yang menyatakan, promosi adalah :

1. Swastha dan Irawan (2005:349) Menurut Swastha dan Irawan, Promosi adalah arus informasi atau persuasi satu arah untuk mengarahkan seorang atau organisasi terhadap tindakan yang menciptakan pertukaran dalam pemasaran.

2. Kotler (2000:119) Menurut Kotler, Promosi adalah bagian dan proses strategi pemasaran sebagai cara untuk berkomunikasi dengan pasar dengan menggunakan komposisi bauran promosi "promotional mix".

Sedangkan dalam (Permana, 2017) Menurut Tjiptono (2014) promosi terhadap jasa lebih membutuhkan penekanan untuk meningkatkan kualitas jasa yang telah dilakukan. Promosi tidak hanya mengenalkan suatu produk atau keunggulan pada produk tersebut namun kegiatan promosi dimaksudkan untuk dapat berkomunikasi dengan konsumen, sehingga perusahaan dapat memperkenalkan, membujuk, mempengaruhi, maupun mendorong konsumen untuk membeli produk maupun jasa yang telah ditawarkan perusahaan pada konsumen.

Tujuan Promosi Adapun tujuan dilakukan promosi yaitu:

1. Untuk menyebarluaskan nformasi barang atau jasa perusahaan kepada pasar

2. Untuk mendapatkan konsumen baru dan menjaga kesetiaan konsumen untuk membeli dan menggunakan produk atau jasa perusahaan.

3. Untuk meningkatkan penjualan sehingga pendapatan perusahaan akan meningkat,

4. Untuk membedakan dan mengunggulkan produk perusahaan dibandingkan dengan produk pesaing.

5. Untuk membentuk citra produk atau jasa dan juga nama perusahaan dimata konsumen.

6. Untuk mengubah tingkah laku dan pendapat konsumen

\section{B. Aplikasi Canva}

Setelah mengetahui pentingnya promosi dalam setiap kegiatan, peserta belajar membuat desain promosinya. Dalam pembuatan desain, sebenarnya ada beberapa aplikasi/program yang bisa di pakai, seperti photoshop. Namun dalam kegiatan 
pengabdian masyarakat ini kami memutuskan menggunakan aplikasi Canva karena beberapa pertimbangan,

1) Canva merupakan salah satu aplikasi gratis dan menawarkan banyak template untuk melakukan desain grafis.

2) Penggunaan aplikasi Canva dapat meningkatkan kreativitas dalam membuat desain poster, presentasi, dan konten visual lainnya.

3) Bisa dilakukan dengan menggunakan atau laptop.

Dalam kegiatan yang dilakukan oleh (Santi et al., 2020), (Sholeh, Rachmawati and Susanti, 2020), dan (Wicaksana, Atmadja and Asmira, 2020) menjadi rujukan aplikasi Canva dapat digunakan untuk banyak hal di berbagai bidang seperti bidang wirausaha mahasiwa, pelaku UMKM dan bidang pendidikan di sekolah dalam kegiatan pembelajaran.

Adapun salahsatu factor yang mempengaruhi pelatihan ini menjadi mudah di cerna karena para peserta langsung paraktik dalam pelaksanaan pelatihannya, mulai dari download aplikasi di playstore, registrasi di www.canva.com sampai pada membuat desain dan konten. Sehingga kendala hampir tidak ada.

Pelaksanaan kegiatan berjalan dengan lancar dan peserta pelatihan terlihat antusias dalam mengikut materi, hal tersebut dibuktikan dengan keaktifan peserta dalam bertanya dan mempraktikan pembuatan desain. Rincian kegiatan diperlihatkan dalam tabel 1 di bawah ini.

Tabel 1 Jadwal Kegiatan Pelatihan

\begin{tabular}{|c|c|c|c|}
\hline No & Kegiatan & Waktu & Pelaksana \\
\hline 1 & Pembukaan & $08.00-08.30$ & Pembawa Acara \\
\hline & $\begin{array}{l}\text { a. Pembukaan } \\
\text { b. Sambutan ketua Yayasan/ mewakili } \\
\text { c. Sambutan Ketua Pelaksana PM ( Ibu Ety } \\
\text { Nurhayaty) }\end{array}$ & & $\begin{array}{l}\text { Bapak Eigis } \\
\text { Pramularso }\end{array}$ \\
\hline 2 & Materi 1: Pentingnya Promosi & $08.30-09.00$ & $\begin{array}{l}\text { Ibu Isnurrini Hidayat } \\
\text { Susilowati }\end{array}$ \\
\hline 3 & Materi 2 : Praktikum Canva dan soal Latihan & $09.00-12.00$ & $\begin{array}{l}\text { Ibu Ratnawaty } \\
\text { Marginingsih }\end{array}$ \\
\hline 4 & Penutupan dan Doa & $12.00-12.30$ & $\begin{array}{l}\text { Pembawa Acara } \\
\text { Bapak Eigis Yani } \\
\text { Pramularso }\end{array}$ \\
\hline
\end{tabular}

Pada pelaksanaan kegiatan ini, tidak mendapatkan kendala berarti, walaupun pelaksanaan kegiatan menggunakan perpaduan antara live youtube, dan praktik di lokasi. Karena seluruh sarana dan prasarana sudah dipersiapkan sejak beberapa hari menjelang pelaksanaan. Selain itu petugas atau operator dari pihak yayasan juga cukup sigap menangani segala kendala teknis di lokasi sehingga sangat membantu memperlancar kegiatan dari awal sampai akhir. 
Adapun output dari kegiatan ini, meningkatnya kemampuan pengurus dan relawan yayasan dalam membuat desain sehingga mampu menghemat pengeluaran untuk membayar jasa desain banner atau media promosi untuk setiap kegiatan bahkan dapat menjadi sumber pemasukan baru bagi Yayasan untuk menambah dana operasional dalam menjalankan program dengan lebih baik. Berikut adalah beberapa dokumentasi kegiatan tersebut:

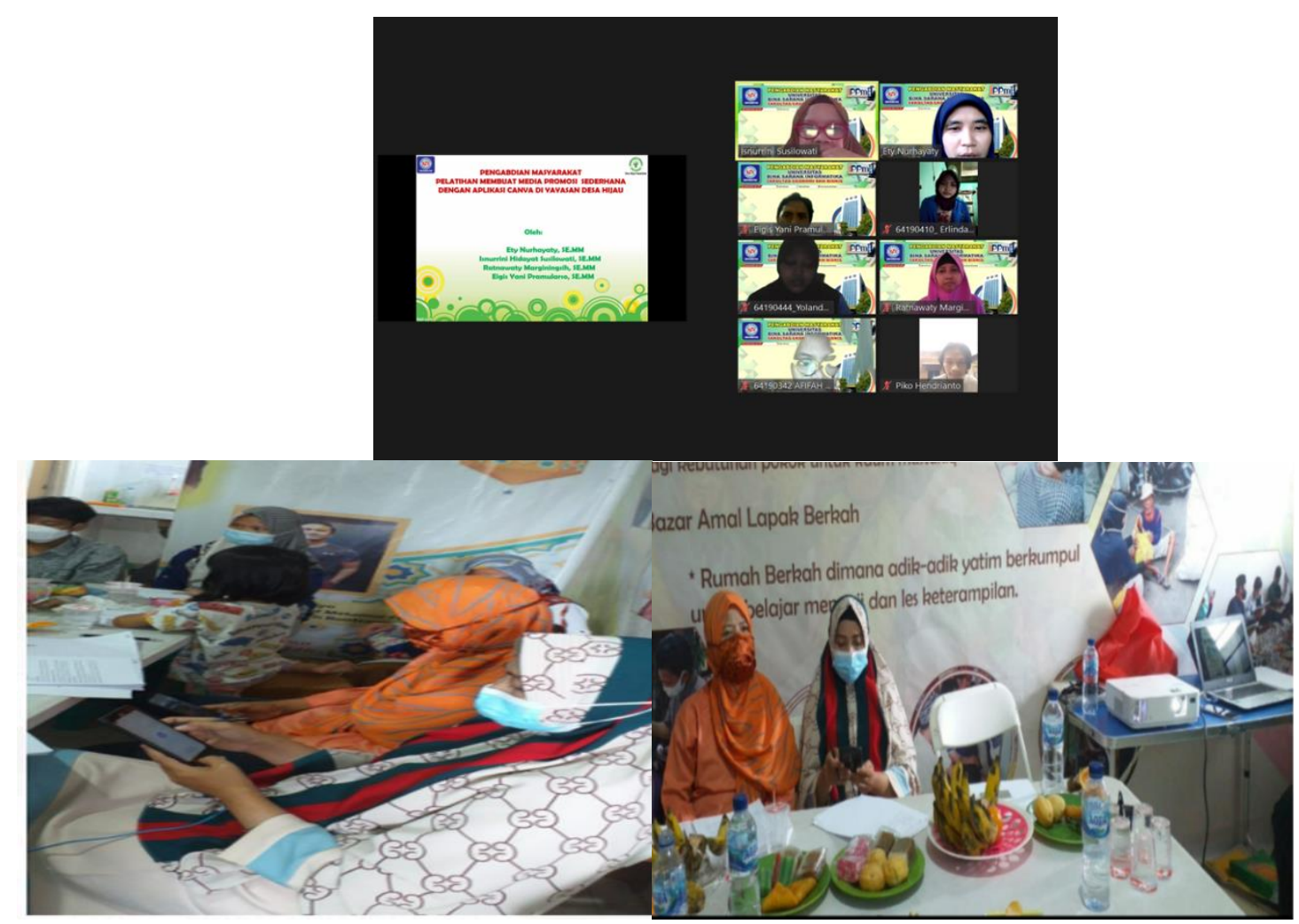

Gambar 1 : Kegiatan selama Pelatihan Membuat Media Promosi Sederhana Dengan Aplikasi Canva Di Yayasan Desa Hijau

Sedangkan hasil karya para peserta yang telah berhasil menyelesaikan tugas pembuatan banner dengan desain canva, adalah sebagai berikut:
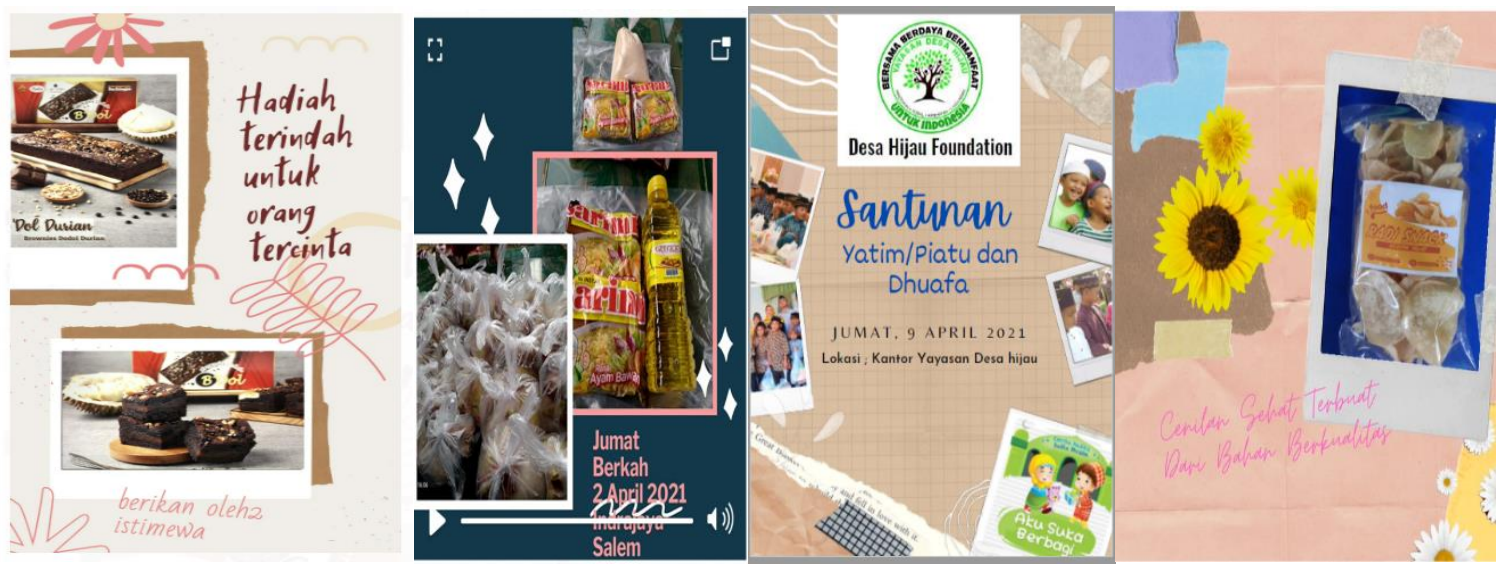

Gambar 2: Hasil Karya Peserta 


\section{Simpulan dan Rekomendasi}

Diakhir kegiatan pengabdian masyarakat ini kami membagikan kuesioner tentang seberapa puas mereka dengan materi yang kami berikan, dan dari hasil kuesioner tersebut, 100\% merasa puas dan menyatakan bahwa kegiatan ini sangat bermanfaat bagi mereka, bahkan dari kolom saran yang kami sediakan, beberapa dari mereka menginginkan dan meminta kembali untuk memberikan materi lanjutan terkait kegiatan yayasan seperti pembuatan laporan keuangan, Teknik presentasi dan lainnya yang pada intinya mendukung kegiatan di Yayasan agar dalam operasional sehari-hari dapat lebih efisien dan efektif.

\section{Penghargaan}

Terima kasih kepada pengurus dan relawan Yayasan Desa Hijau asuhan dari bapak Heru Kusdiyono, selaku pendiri dan ketua Yayasan yang beralamat di Jl. Masjid AtTauhid, Jl. Haji Kuming 2 No. 123, RT 04/RW 12, Kedaung, Pamulang, Tangerang Selatan 15415. Semoga seluruh kegiatan sosial kemasyarakatannya mampu membantu meringankan beban warga dhuafa dan senantiasa berguna bagi masyarakat sekitar pada khususnya.

\section{Daftar Pustaka}

Alma, B. and Hurriyati, R. (2009) Manajemen corporate dan strategi pemasaran jasa pendidikan fokus pada mutu dan layanan prima. Bandung: Alfabeta.

Garaika, Winda Feriyan.(2019).Promosi Dan Pengaruhnya Terhadap Terhadap Animo Calon Mahasiswa Baru Dalam Memilih Perguruan Tinggi Swasta. Jurnal Aktual STIE Trisna Negara Volume 16 (1) Juni 2018, Hal. 21-27 ISSN : 1693-1688

Ghalib Huda, Achmad Hendra Setiawan.(2019) Analisis Perbedaan Sebelum Dan Sesudah Penggunaan Media Sosial Terhadap Perkembangan Usaha Catering Di Kota Semarang. Diponegoro Journal Of EconomicS Volume 1 Nomor 1 Tahun 2019, halaman 1 https://ejournal2.undip.ac.id/index.php/dje ISSN (Print) : 2337-3814 1

Halim, C. (2013) Tip Praktis Promosi Online untuk Berbagai Event. Jakarta: Elex Media Komputindo.

Maulidasari cet Devi, Damrusb. (2021) DAMPAK PROMOSI PRODUK PADA PEMASARAN ONLINE Jurnal Bisnis dan Kajian Strategi Manajemen Volume

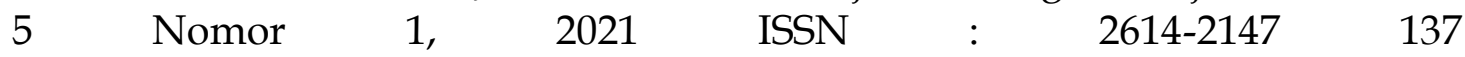
http://jurnal.utu.ac.id/jbkan/article/view/3464/2060\#

Permana Dony Indra (2017). PENGARUH PROMOSI TERHADAP KEPUTUSAN PEMBELIAN PRODUK LANTAI KAYU DAN PINTU PT.PIJI DI JAWA TIMUR . PERFORMA: Jurnal Manajemen dan Start-Up Bisnis Volume 2, Nomor 1 1, April 2017

https://journal.uc.ac.id/index.php/performa/article/view/444/397

Rahmatullah, R., Inanna, I. and Ampa, A. T. (2020) 'Media Pembelajaran Audio 
Visual Berbasis Aplikasi Canva', Jurnal Pendidikan Ekonomi Undiksha, 12(2), pp. 317-327.

Santi, I. N. et al. (2020) 'Pelatihan Membuat Logo Usaha Menggunakan Aplikasi Canva Bagi Mahasiswa Wirausaha', Jurnal Pengabdian pada Masyarakat, 8(November), pp. 41-45.

Sholeh, M., Rachmawati, R. Y. and Susanti, E. (2020) 'Penggunaan Aplikasi Canva Untuk Membuat Konten Gambar Pada Media Sosial Sebagai Upaya Mempromosikan Hasil Produk Ukm', SELAPARANG Jurnal Pengabdian Masyarakat Berkemajuan, 4(1), p. 430. doi: 10.31764/jpmb.v4i1.2983.

Tanjung, R. E. and Faiza, D. (2019) 'Canva Sebagai Media Pembelajaran Pada Mata Pelajaran Dasar Listrik Dan Elektronika', Jurnal Vokasional Teknik Elektronika dan Informatika, 7(2), pp. 79-85.

Unonongo Wulanytha, Deasy Warouw dan Lingkan Tulung (2015) Fungsi Promosi Dalam Meningkatkan Daya Beli Gadget Samsung Di Kota Manado Jurnal Acta Diurna Vol 4 no.5 https://media.neliti.com/media/publications/92615ID-fungsi-promosi-dalam-meningkatkan-daya-b.pdf

Valentino Dion Eko, Yudiansyah.(2020). Perancangan Desain Grafis Sebagai Media Promosi Pada Novena Hotel Bandung. Jurnal Teknologi Informasi Komunikasi (e-Journal) - Vol 7 No 2 (2020): Tematik : Desember 2020 https://jurnal.plb.ac.id/index.php/tematik/article/view/486/322

Waluyo Sudardi, efri syamsul bahri, ending ahmad yani (2015) Pengaruh Promosi terhadap Perolehan Dana Zakat, Infaq, dan Shadaqah (Studi Kasus pada Yayasan Imdadt Mustadh'afin). Jurnal Rausyan Fikr https://www.researchgate.net/publication/343240642_Pengaruh_Promosi_te rhadap_Perolehan_Dana_Zakat_Infaq_dan_Shadaqah_Studi_Kasus_pada_Ya yasan_Imdadt_Mustadh\%27afin

Wardhanie ayouvi Poerna, Fenty Fahminnansih, Endra Rahmawati (2021) Pemanfaatan Aplikasi Canva untuk Desain Grafis dan Promosi Produk pada Sekolah Islami berbasis Kewirausahaan. https://doi.org/10.37802/society.v2i1.170 https://ejournals.dinamika.ac.id/index.php/society/article/view/170/123

Wicaksana, E. J., Atmadja, P. and Asmira, Y. (2020) ‘Pengembangan Poster Kesehatan Reproduksi Berbasis Pendidikan Karakter Menggunakan Canva pada Usia Remaja Sekolah di SMA', Jurnal Penelitian dan Pengkajian Ilmu Pendidikan: eSaintika, 4(2), p. 160. doi: 10.36312/e-saintika.v4i2.215. 